\title{
HACIA UNA CARTOGRAFÍA DE LA CRIANZA: DOMESTICIDAD Y DOMESTICACIÓN EN COMUNIDADES ANDINAS
}

\author{
VERÓNICA SOLEDAD LEMA ${ }^{1}$ \\ UNLP/CONICET
}

\begin{abstract}
RESUMEN: Una mirada analítica que considere las lógicas nativas vinculadas a las prácticas de manejo o relación que las sociedades mantienen con las comunidades vegetales en los Andes, conduce a destacar el lugar que ocupan las prácticas de crianza mutua como metapratron relacional entre humanos y no humanos. El estudio de las mismas nos lleva a considerar una nueva óptica para abordar procesos de domesticación y manejo de poblaciones vegetales, donde el análisis de la espacialidad de estas prácticas resulta esencial. En este trabajo veremos cómo el ejercicio de la crianza redefine los espacios domésticos más allá de la "casa" en sentido restringido, habilitando el carácter doméstico -aunque no siempre domesticado- de ciertas poblaciones vegetales a nivel local, impactando en las trayectorias evolutivas particulares de los taxa involucrados. La crianza de las plantas nos llevará también a considerar distintos ámbitos esenciales en la reproducción de esta red de sociabilidad ampliada, analizando no solo los espacios de cultivo sino también los almacenes y su rol en la crianza de semillas.
\end{abstract}

PALABRAS CLAVE: crianza; Andes; domesticación; almacenaje; doméstico.

ABSTRACT: An analytical comprehension of the native ways of perceiving the relationship and management practices that societies have with plant communities at the Andes, conduces us to highlight the place that the local practices of mutual nurturing have, as a relational metapattern between humans and non humans. Studying these practices leads us to consider a new optic to address domestication processes and management practices of plants, being the analysis of its spatiality an essential aspect. In this paper we will look at the way in which the exercise of nurturing redefines domestic spaces in a broader sense that the "household" has in a restrictive meaning, allowing the domestic -although not always domesticated-status of some plant populations at a local level, having an impact in the evolutionary trajectories of those taxa involved. Plant nurturing will take us to consider different spots which are essential in the reproduction of the network of amplified sociability, being necessary to analyze not only the places of cultivation but also the places for storage and their role in the nurturing of seeds.

KEYWORDS: nurturing; Andes; domestication; storage; domestic.

\footnotetext{
${ }^{1}$ Licenciada en Antropología. Doctora en Ciencias Naturales. Investigadora asistente del CONICET. Docente de la cátedra de Botánica Aplicada (Facultad de Ciencias Naturales y Museo, Universidad Nacional de La Plata). E-mail: vslema@hotmail.com .
}

Espaço Ameríndio, Porto Alegre, v. 8, n. 1, p. 59-82, jan./jun. 2014. 
VERÓNICA SOLEDAD LEMA - Hacia una cartografía de la crianza...

\section{Palabras iniciales}

Este trabajo apunta a repensar las consideraciones acerca de lo domestico y sus manifestaciones materiales desde la lógica relacional de la crianza mutua (APAZA TICONA, GORDILLO CONDORI y CUTIPA, 1998) en tanto gramática de la sociabilidad andina (LEMA, 2013; PAZZARELLI, 2013). Si bien posee un plano discursivo, la crianza es un ejercicio práctico que implica una espacialidad cargada de significaciones que los conceptos nacidos de esta gramática habilitan.

Pensar a la crianza en términos de red de relaciones que se tejen en el espacio, no implica pensar que quienes se ven implicadas en ella (humanos y no humanos) son equivalentes en términos de interioridad, exterioridad o potencia (CAVALCANTI-SCHIEL, 2007; LEMA, 2013; PAZZARELLI, 2013). En las siguientes líneas me centraré en las relaciones de crianza que involucran a las plantas, una partición de la red antes mencionada que se hace para explorar las particularidades de la misma, sin dejar de atender al contexto general en el que se ven implicadas las mismas. Tras atender a las dinámicas de las plantas y sus criadores en el paisaje, me centrare, al final del texto, en la crianza mutua entre humanos y plantas y cómo la misma se materializa en el espacio de las unidades domésticas y en el cuerpo de las plantas. A lo largo del texto ciertas decantaciones académicas de las nociones de domestico y domesticado se irán tornasolando al ser intervenidas por las formas locales de entender cómo se es y se está en un mundo de sociabilidad fluida.

El escrito se nutre de bibliografía desarrollada en el ámbito andino y de la experiencia compartida en comunidades del Noroeste de Argentina (NOA) y Perú.

\section{Domesticación, domesticidad y crianza}

En la gramática relacional de la crianza o uywaña (MARTíNEZ, 
VERÓNICA SOLEDAD LEMA - Hacia una cartografía de la crianza...

1976) se incluyen -entre otros aspectos- diferentes prácticas y procesos que solemos particionar en categorías tales como domesticación, recolección y cultivo.

La crianza es un modo de sociabilidad entre humanos y no humanos presente en gran parte del mundo andino, pudiendo haber casos en los que la misma se rompa, los seres salgan de este entramado y padezcan consecuencias percibidas como negativas. Esta crianza mutua que implica "cultivo, protección, aliento, amparo" (RENGIFO VÁSQUEZ, 1999, p. 132) entre diversos seres es "la vida dulce", lo cual no quita que esté exenta de conflictos (RENGIFO VÁZQUEZ, 2002). Su práctica se vincula no solo al cultivo de plantas (LEMA, en prensa) y al cuidado de los animales (BUGALLO y TOMASI, 2012), sino también al cuidado que se prodigan los humanos entre sí y los humanos con otros no humanos.

La condición de criador y criado cumplida al unísono es compartida por muchos seres en los Andes, aunque con capacidades no siempre equivalentes (LEMA, 2013; PAZZARELLI, 2013). Todos crían chacra (el cerro, los seres humanos, ciertos animales) y son criados por la chacra que crían, por lo cual, en el mundo aymara, conceptualmente "chacra"2 es todo aquello que se cría (VALLADOLID RIVERA, 1994). En los Andes chilenos, esta categoría unifica también a todos los espacios de crianza de especies vegetales (ALDUNANTE et al., 1981). En el NOA, en cambio, refiere en varios casos exclusivamente al maíz (LEMA, en prensa y 2013). En este sentido, Mayer (2004) se opone a la noción de "unidad doméstica" (household) forjada en el seno de la antropología económica, la cual separa a la casa/vivienda/residencia de las áreas de producción, para ver luego cómo se relacionan, ya que en los Andes "los campos también forman parte de la unidad doméstica, son el lugar donde las semillas se convierten en cosechas" (MAYER, 2004, p. 21). Esto se ve en algunas comunidades $(*)^{3}$ donde la chacra es el espacio donde se ubica la residencia de la familia, sus cultivos y animales de cría. En otro

\footnotetext{
${ }^{2}$ Escribiré el término chacra entre comillas cuando lo empleé en este sentido conceptual a lo largo del texto.

${ }^{3}$ Se señalará con un asterisco $(*)$ en el texto la experiencia en una comunidad de la región de Huánuco, Perú, realizada en el marco del curso "Domesticación, manejo y conservación in situ de recursos genéticos", dictado por el Dr. Alejandro Casas (Universidad Nacional Autónoma de México) y el Ing. Juan Torres Guevara (Universidad Nacional Agraria La Molina), en 2011.
}

Espaço Ameríndio, Porto Alegre, v. 8, n. 1, p. 59-82, jan./jun. 2014. 
VERÓNICA SOLEDAD LEMA - Hacia una cartografía de la crianza...

trabajo (LEMA, en prensa) señalé como, por ejemplo, en la comunidad aborigen de Huachichocana (Depto. de Tumbaya, Jujuy, NOA) la presencia de árboles sembrados en los domicilios y en las proximidades de los canales de riego señala en qué medida viviendas y áreas de trabajo agrícola (áreas de terreno donde se crían plantas, áreas donde se cría el agua) están unidos por las manifestaciones materiales que indican habitabilidad y cotidianeidad. Así como la casa ${ }^{4}$ es el espacio físico que alberga y reproduce a los miembros humanos de una unidad doméstica, los espacios productivos de crianza gestionados por estos (chacra, rastrojo, quinta, sembradío, corrales, potreros, acequias), son los ámbitos que albergan y reproducen a los miembros no humanos de dicha unidad: "amparar una casa es vivir en ella para que otro no se la apropie, amparar un terreno es regarlo y cortar la alfalfa" (GARCíA et al., 2002 , p. 99), atender o amparar un potrero de alfa es regarlo, los corrales son la casa de la hacienda (GÖBEL, 2000/2002; TOMASI, 2011; BUGALLO y TOMASI, 2012). Estos desplazamientos semánticos de prácticas por diferentes espacios físicos señala cómo los ámbitos productivos forman parte de la unidad doméstica y cómo la cotidianeidad de las prácticas de crianza articulan, entretejen y unifican la crianza de la vida dentro de ella: el alfa almacenada es la ración de la haciendita y la vega ${ }^{5}$ es el sostén del ganado (GARCíA et al., 2002, p. 92-93). La relación espacial de casas y campos objetiva y es el soporte material para la reproducción de prácticas cotidianas de laboreo agrícola (QUESADA y KORSTANJE, 2010), asimismo el traslado hacia puestos o estancias se da porque "la hacienda tiene sus propios gustos y necesidades, igual que las personas" (TOMASI, 2011, p. 294). Estos espacios de crianza humana también se evidencian en la crianza del agua mediante canales y acequias (LEMA, en prensa; QUESADA, 2007). Hemos visto como en el caso de ciertas comunidades de la Quebrada de Humahuaca (NOA), el agua puede ser devastadora cuando las fuertes lluvias del estío generan volcanes (aludes de agua y barro) que tienen consecuencias desastrosas en el paisaje, o bien puede volverse

\footnotetext{
${ }^{4}$ Se escriben en cursiva términos locales.

5 Área caracterizada por una elevada concentración de humedad -generalmente por cercanía a una vertiente, laguna o río- lo que genera una asociación peculiar de gramíneas y una edafología propias, en ciertas zonas de regiones altoandinas.
}

Espaço Ameríndio, Porto Alegre, v. 8, n. 1, p. 59-82, jan./jun. 2014. 
VERÓNICA SOLEDAD LEMA - Hacia una cartografía de la crianza...

productiva cuando entra a la red de crianza humana a través de los canales y acequias para el riego, siendo asimismo usado el depósito de barro que deja tras su paso como asiento de una nueva área de cultivo.

La idea de un espacio de residencia de los humanos junto a los animales y plantas que los mismos producen se plasma en la palabra latina domus, de la cual se derivaría la palabra domesticación, como opuesto a lo salvaje o silvestre del agrios (HODDER, 1992; HARLAN, 1992). Esta división espacial se traduce en términos conceptuales a aquellos lugares donde los humanos tienen o no -respectivamentecontrol de los sucesos y procesos que se dan en torno a quienes lo habitan. Domesticar terminó entendiéndose como la transformación práctica y simbólica de traer lo silvestre al hogar y modificarlo (controlarlo y sujetarlo a los deseos humanos) enfocándose su estudio en las relaciones y prácticas de transformación de la naturaleza y la definición de las unidades sociales de apropiación de la misma (HABER, 2006; HARLAN, 1992).

El sentido de domesticación en su doble acepción de incorporar al domus y alcanzar el control o dominio del otro vegetal/animal en la lógica de entendimiento occidental y académico se halla subvertido en las comunidades andinas en, al menos, dos sentidos. Uno de ellos es que no existe la idea de control absoluto sobre las comunidades vegetales que los humanos producen. En estudios llevados a cabo tanto en Europa-Asia y en el NOA (HODDER, 1992; HARLAN, 1992) se interpretan los procesos históricos vinculados al Neolítico y al Formativo respectivamente como un período donde puede verse la sujeción de los cuerpos animales y humanos a relaciones sociales estructuradas, produciéndose una domesticación de ambos en el espacio de los compuestos domésticos donde se materializa dicha domesticidad. La asociación domesticidad-dominio se refleja en personas que se vuelven cuerpos dóciles, sujetados, domados, atrapados (HODDER, 1992) al igual que los animales que domestican, una dialéctica entre dominación y naturalización (HABER, 1997 y 2006).

Lejos de pensarse y ejecutarse en los términos de sujeción o dominio, la crianza humana de plantas es más cercana a lo que académicamente entendemos por cultivo (en el sentido de un cuidado intencional (LEMA, 2009)) que por domesticación, cuyo diacrítico es el 
VERÓNICA SOLEDAD LEMA - Hacia una cartografía de la crianza...

control de los sistemas reproductivos y de dispersión de plantas y animales en manos del Hombre (HILLMAN y DAVIES, 1990). La crianza andina no parece generar grados mayores de dependencia entre humanos y plantas en el sentido en que se ha entendido esta categoría conceptual (HARRIS, 1989; LEMA, 2009), de hecho, muchos de los cultivos americanos no son domesticados en el sentido estricto antes señalado. Diversidad, interacción, limites transponibles o traspasables caracterizan las prácticas de crianza mutua en los Andes, una domesticidad pactada, dinámica e interactiva, constructora de multiplicidades, antes que de sujeción o de dominio. Esto se manifiesta en la presencia de complejos "silvestre-maleza-cultivado" (BEEBE et al., 1997; LEMA, 2009) en los espacios productivos (principalmente huertos6), que indican la ausencia de las biparticiones o dicotomías antes mencionadas, siendo los espacios manufacturados de crianza porosos y dúctiles.

El segundo sentido al que quiero referirme es que la crianza no es patrimonio exclusivo de los humanos, muchos no humanos son criadores, habiendo entre ellos seres potentes que también crían a los humanos y posibilitan su rol de criadores (GIL GARCÍA Y FERNÁNDEZ JUÁREZ, 2008; LEMA, 2013; PAZZARELLI, 2013; RIVERA ANDÍA, 2008). A su vez, existe una flexibilidad de relaciones entre un ámbito criado y estructurado por los humanos y otro criado y estructurado por seres de una gran potencia (como los cerros). Estas son esferas que se interconectan entre sí por ser -a su vez- mutuamente criadas, en una gramática de la sociabilidad donde la pactación y el pago como formas del acuerdo y el diálogo, se hacen parte de esa intertextualidad.

La falacia de la división de un ámbito "natural" y otro "doméstico" lo destaca Descola (2012) al advertir que en el pensamiento amerindio e incluso en otras sociedades del llamado "Viejo Mundo"- existe un gran continuum social en el que se mezclan humanos y no humanos, por lo que al prolongar el mundo familiar a lo que nosotros llamamos

\footnotetext{
${ }^{6}$ La presencia de complejos bioculturales que incluyen por igual plantas silvestres, manejadas y domesticadas, suele tener lugar en los huertos, espacios productivos fuertemente ligados a la unidad doméstica, lo que se evidencia espacialmente en su emplazamiento próximo o adosado al espacio residencial de la misma, pudiendo ser incluso una transmutación de los patios (GLEASON, 1994). En el NOA, los huertos poseen diseños y emplazamientos variables, siempre próximos a las viviendas (LEMA, 2006).
}

Espaço Ameríndio, Porto Alegre, v. 8, n. 1, p. 59-82, jan./jun. 2014. 
VERÓNICA SOLEDAD LEMA - Hacia una cartografía de la crianza...

"naturaleza", la misma se convierte en algo verdaderamente doméstico hasta en sus reductos más inaccesibles. El denso entramado social de la crianza mutua, conlleva una gramática marcada por pagos y pactos entre criadores en un paisaje que se concibe interlocutor y comensal, donde la interfagocitación entre seres es usual (BUGALLO y VILCA, 2011; VAN KESSEL, 2003; VILCA, 2009).

Las plantas son incompletas como los humanos (PRATEC, 1999) por ello necesitan ser criadas. Al igual que los humanos y otros no humanos, crían y, en el caso de las que están en los espacios de cultivo de los Hombres, crían a los humanos. En el caso de las plantas -además de ser criadas por "apus u orccos" como ocurre con ciertos animalesson también criadas por animales como, por ejemplo, el zorro (PRATEC, 1999; LEMA, 2013). Asimismo, al igual que los humanos, las plantas (y los animales) crían a sus propios hijos, siendo el caso de la papa y otras plantas tuberosas, paradigmático a este respecto (APAZA TICONA, 2000; ARNOLD y YAPITA, 1996). Las plantas tienen también relaciones de parentesco entre sí, aunque este parentesco no se da siempre en el sentido de un progenitor silvestre -en el sentido académico de este último término- sino por la presencia de las maman o madres de las que procede un cultivo (PRATEC, 1999; LEMA, 2013) y que lo posibilitan por antecederlos en el mismo espacio de crianza (la mashua es la madre de la oca y esta de la papa en un mismo sector de crianza humana*, un planta particular de papa puede concebirse como la madre de todas aquellas que son sembradas en las distintas patías de un sector sembrado, proteger a esta planta madre con una olla invertida de las heladas protege a todas sus "hijas" de las inclemencias del tiempo; LEMA, 2006; POCHETTINO y LEMA, 2008).

En las próximas secciones analizaremos cómo los cuerpos y comportamientos de las plantas criadas cambiarán de acuerdo con la red de crianza en donde se vean inmersas, así como también lo harán si abandonan los términos de la sociabilidad que esta implica. Analizaremos también como los humanos no son los únicos criadores ni los únicos criados, teniendo las plantas que crían los Hombres análogos entre las que crían otros seres. Parecería ser que existe un continuum de interioridades de plantas entre uno y otro ámbito de crianza, cambiando sus naturalezas, sus cuerpos, sus exterioridades, sin que 
VERÓNICA SOLEDAD LEMA - Hacia una cartografía de la crianza...

esto último responda necesariamente a cambios en la espacialidad. Veremos cómo en el ámbito domestico donde crían los humanos, estos amparan también plantas de otras entidades, si bien lo opuesto no es siempre el caso.

Dinámicas en la espacialidad: trayectorias de cambios

Si consideramos que no es solamente la reproducción de la sociabilidad humana lo que se vincularía a las unidades domésticas (casas y puestos), sino también la espacialidad donde habita aquello que es criado por el Hombre (quintas, sembradíos, rastrojos, acequias y corrales) la crianza humana estaría definiendo lo domestico y delimitando su ámbito. En contraposición, los espacios donde los humanos no ejercen prácticas de crianza podrían entenderse como no domésticos dado que la sallqa (a diferencia de uywa) es un dominio que posee plantas y animales criados por entes no humanos (GRILLO FERNÁNDEZ, 1994). Sin embargo esta aparente división se va desdibujando en términos espaciales, de prácticas y exterioridades de criados y criadores. Este es el caso de los pastoreos (TOMASI, 2011) ya que la hacienda, come cerro, un ámbito donde el alimento de los animales de crianza humana procede de las plantas que son criadas por el cerro, el mismo que consumen los animales que cría éste, donde pasta la hacienda de Coquena (PAZZARELLI, 2013). Las vegas o cienegos pueden ser criadas mediante riego (GARCíA et al., 2002; QUESADA, 2007) al igual que otras plantas no domesticadas (como el espuru Sporobolus rigens - en Huachichocana) para alimentar a los animales de cría. Por lo general, esta práctica no genera a nivel local una nueva categoría espacial que las distinga (se sigue refiriendo a estos espacios como vega o como espuru), aunque a veces sí se le da un nuevo nombre, como en Antofagasta de la Sierra donde las vegas criadas se denominan potrerillos (QUESADA y LEMA, 2012). Esto resulta interesante ya que indica un desplazamiento semántico entre estas áreas criadas para alimentar a la hacienda (incluso a la hacienda no humana) y los 
VERÓNICA SOLEDAD LEMA - Hacia una cartografía de la crianza...

espacios donde se siembra alfa (potreros) ${ }^{7}$ (LEMA, en prensa).

Además de una interioridad que hace que las plantas se vinculen a criadores [una "incompletitud" (PRATEC, 1999) compartida con los humanos], las plantas -y otros seres no humanos- poseen también la capacidad de anidar diversas formas. Las plantas adquieren otros cuerpos cuando salen de la "chacra" humana (en un proceso que llamaríamos académicamente "asilvestramiento") y esto ocurre porque las plantas caminan entre las "chacras" de humanos y no humanos debido a la falta de atención y cariño (PORCEL GIRA Y QUISPE FLORES, 2010; PRATEC, 1999), un descuido que solo parecen tener los primeros. Parte de la interioridad de las plantas hace que estas reconozcan cuando no son bien atendidas, por lo cual deciden abandonar a su criador. Esto se menciona para las plantas que se vuelven apharu, pudiendo salir del ámbito físico de las chacras humanas incorporándose a la chacra de los achachilas (cerros- deidad), lo cual no quita la posibilidad al criador humano de usar estos apharus como semillas nuevamente para sus chacras (PRATEC, 1999). En Rachaite (Puna de Jujuy) obtuvimos referencias acerca de la ajara y el ataco como formas silvestres/asilvestradas de la quínoa (Chenopodium quinoa) y de la quiwicha (Amaranthus sp.) respectivamente (LEMA, 2006). Nos refirieron que cuando la quínoa no es cosechada por dos o tres años, se vuelve ajara. Si bien en líneas generales las personas referían que ambas no se consumen como alimento o se siembran, sino que son alimento de la hacienda o bien se emplea la ajara para hacer lejía para mascar coca, vimos que algunas familias tenían en sus almacenes ajara. En un único caso nos afirmaron que la misma se siembra y en otro que el ataco se cosecha, se lo lava y se lo echa a la sopa. También se nos refirió que si la papa se deja sin cosechar por dos o tres años se vuelve aparoma.

Se entiende que cuando una planta cultivada domesticada "escapa de cultivo" -como suele decirse en el ámbito agronómico- se asilvestra, es decir, vuelve a adquirir caracteres de la forma antecesora, perdidos bajo manejo humano. En este último caso -como el que mencionamos antes para la quínoa/ajara, la quiwicha/ataco o las aparoma- la espacialidad de las poblaciones se ve reflejada en la morfología de las

\footnotetext{
${ }^{7}$ Este desplazamiento semántico tiene también un sustento histórico (ver QUESADA y LEMA, 2012).
} 
VERÓNICA SOLEDAD LEMA - Hacia una cartografía de la crianza...

plantas, dependiendo de qué lado estén del límite productivo humano y del tiempo transcurrido en un ámbito de crianza o en otro. Sin embargo, puede darse el caso de plantas que traspasan el "límite productivo" de los rastrojos criados por los humanos sin que ello implique una nueva categoría de clasificación. Este es el caso del alfa (alfalfa, Medicago sativa) que sale con el agua que derraman las acequias al campo o a la playa de los ríos e incluso, allí donde hay agua, se cría solita (LEMA, en prensa y 2013). Esto que veríamos como un traspaso, un "escape de cultivo" no genera que la misma se desdoble localmente en dos categorías tales como planta domesticada versus maleza y tampoco es vista como planta del cerro. La capacidad de esta planta de "crecer solita" y la ausencia de cambio morfológico en las poblaciones que están por fuera de los espacios de crianza, hace que su espacialidad no juegue un rol destacado en su reconocimiento e identificación, sigue siendo alfa. De igual forma, plantas como la cacala (Nicotiana glauca) que son abundantes en las playas de los ríos y en los terrenos afectados por el volcan en Huachichocana, pueden presentarse en las quintas anexas a los espacios residenciales que, tan solo por el hecho de estar allí, son ocasionalmente referidas como domésticas (LEMA, en prensa).

Existen también casos de cuerpos vegetales que señalan a los criadores, desligados de la espacialidad. Es el caso de las plantas sachas que viven en la "chacra" humana. Si bien las sachas (sallqas en algunos casos) parecen ser siempre una contraparte de plantas criadas por humanos (papa, oca, quínoa, maíz, por ejemplo) ello no significa que la sacha sea necesariamente un antecesor silvestre de la planta cultivada; es sólo por sus características externas y algunos otros atributos que se hace esta homonimia, agregando a la planta criada por el monte, el prefijo sacha, seguido del nombre que le corresponde a la planta cultivada, por ende, las plantas "sachas", las "apharu" -criadas por los apus- no son necesariamente lo que se entiende por parientes silvestres -si bien a veces pueden serlo-, siendo en algunos casos plantas sin relación genética con la planta cultivada por los humanos (PRATEC, 1999; TAPIA y TORRES, 2002). Es también usual que se traigan plantas de "chacras" no humanas al ámbito de la crianza humana. Así plantas del cerro o del monte acompañan a las cultivadas en las "chacras" de los humanos (LEMA, 2006 y 2013 ; PRATEC, 1999). Usualmente, los sectores

Espaço Ameríndio, Porto Alegre, v. 8, n. 1, p. 59-82, jan./jun. 2014. 
VERÓNICA SOLEDAD LEMA - Hacia una cartografía de la crianza...

sembrados no se deshierban, o se lo hace solo en parte, principalmente porque se requiere el lugar que ocupan las plantas no cultivadas (LEMA, 2006 y en prensa; PRATEC, 1999), o bien porque los cultivos aún no han germinado y estas plantas le ganan debido a su desarrollo más veloz, como nos refirieron en Huachichocana. Asimismo muchas de las plantas que aparecen en los sembradíos y son de utilidad -generalmente medicinales o comida de la hacienda- son atendidas y amparadas al igual que las plantas que fueron sembradas por los criadores humanos en ese mismo lugar. También se siembran semillas de plantas de la "chacra" humana en el monte para que los hombres o los dueños del monte coman a futuro sus frutos (QUINTEROS, 1999). Finalmente, podemos mencionar plantas del cerro que no entran a las "chacras" humana (PRATEC, 1999; LEMA, 2013).

El cambio de los cuerpos -y de sus propiedades como alimenticios o medicinales para los humanos-se da también al interior de un sembradío donde se practica la rotación de cultivos. Vimos en Huachichocana que entre los cultivos de maíz pueden estar presentes plantas del cerro como las papas yutas, las cuales se encuentran asimismo entre los sembradíos de papa, fuera de sus porosos contornos (LEMA, 2013) Es el caso de las k'iphas (PORCEL GIRA y QUISPE FLORES, 2010; PRATEC, 1999) que son los tubérculos que quedan en las parcelas cosechadas y que en años posteriores crecen por sí solos dentro de los cultivos de otras especies.

Vemos por lo tanto, que antes que formas silvestres, domesticadas o antecesores silvestres los distintos tipos de plantas se caracterizan por una fluidez entre criadores humanos y no humanos, pudiendo ser señal de ello una discontinuidad en los cuerpos y/o sus propiedades. Es la red de crianza y de sociabilidad en que se ven insertas estas plantas lo que marca un cambio, que no parecería reflejarse necesariamente -en todos los casos- en la espacialidad que ocupan las mismas. Pero las plantas pueden también salir de esta red de crianza y sociabilidad, irse en vicio, dejar de dar producto (LEMA, en prensa) y reflejar esa "patología social" en un cuerpo donde aquellos órganos que no son empleados por los criadores humanos se ven sobredimensionados (la planta se va en vicio ver LEMA, 2013), una patología que también se ve en los cuerpos humanos (PAZZARELLI, 
VERÓNICA SOLEDAD LEMA - Hacia una cartografía de la crianza...

2013).

Podemos pensar que las prácticas humanas de crianza vegetal se constituyen en tramas no discursivas que se deslizan sobre una urdimbre de significaciones múltiples en el espacio, siendo personas y plantas, lanzaderas del desplazamiento semántico y de la praxis. Se traspasa la frontera entre los espacios "naturales" y "construidos" (en el sentido de manufacturados), se cría sin modificar, se crean espacios bioculturales diversos y porosos, aquello que crían los humanos se objetiva en ámbitos domésticos que son productivos y habitacionales. Allí, los humanos crían plantas con naturalezas (cuerpos) peculiares y amparan también a las que son criadas por el cerro (hecho visible en su cuerpo morfológico y comportamental). En el espacio doméstico los humanos crían a sus familias, a sus animales (la hacienda), amparan también a animales del cerro ( $\mathrm{vg}$. guanacos, patos) y crían también el agua en canales y acequias. En los Andes, parecería ser que -además de discontinuidades en la interioridad y exterioridad que generan una taxonomía ontológica y clasificatoria: $v g$. humanos, plantas, puma, etc.las múltiples naturalezas que distinguen a ciertos seres se relacionan con quien los cría y a quienes crían, una exterioridad que puede ser cambiante y que también se ve afectada -en cuerpos y comportamientopor negarse a esa sociabilidad 8 .

\section{Criar y almacenar}

Si producir es criar, el consumo es ser criado, dejarse criar. La

\footnotetext{
${ }^{8}$ Interioridad y exterioridad se influyen y constituyen recíprocamente. No se está analogando el primer término a lo inmaterial y el segundo a lo material de manera directa y como planos contrapuestos. La exterioridad incluye aspectos objetivables y materiales -morfológicos- al igual que comportamientos que generan discontinuidades que caracterizan a un sujeto (humano o no) y donde se plasman, también, ciertas patologías que su interioridad habilita. La interioridad generaría una continuidad entre seres que poseen la capacidad de dispendiar potencia (CAVALCANTI-SCHIEL, 2007) poseen conciencia reflexiva, intencionalidad, emociones y pueden comunicarse (DESCOLA, 2012) lo cual no quiere decir que todos los seres tengan igual interioridad, poniendo por caso la potencia que tienen los cerros o la pacha en contraposición a humanos, plantas y animales. La exterioridad sería lo "palpable" en el otro con cualquiera de los sentidos de los que se dispone, la interioridad sería lo "inmanente" que se le reconoce como propio. Resulta a este respecto sugerente las referencias en el NOA al ánimu (entidad anímica), a diferencia de la apariencia, distinguiéndose la dimensión anímica de los seres por -por ejemplo- su guapeza y coraje (BUGALLO y VILCA, 2011).
}

Espaço Ameríndio, Porto Alegre, v. 8, n. 1, p. 59-82, jan./jun. 2014. 
VERÓNICA SOLEDAD LEMA - Hacia una cartografía de la crianza...

tecnología productiva - inclusive la tecnología de almacenamiento, transporte y distribución- es saber criar la vida (VAN KESSEL, 2003). La gramática de la crianza conlleva una relación interfagocitaria ya que los humanos, al igual que otras entidades (cerros, pacha) comen los ánimus de otros seres (BUGALLO y VILCA, 2011).

En el caso de la crianza humana de plantas, es interesante considerar algo que particulariza a la misma: el almacenamiento tanto de alimentos como de simientes?.

Las estructuras destinadas al almacenamiento en los Andes son muy diversas, por ejemplo, en Quebrada de Humahuaca (NOA), Ardissone (1937) haciendo un trabajo no exhaustivo en la década del '30, menciona construcciones como las "cestas de cardón"10 para almacenar maíz y trigo desde Maimará a Uquía, "trojas" o "silos" de adobe en los patios de las casa, los cuales podían ser también de piedra y tener divisiones internas para los diferentes cultivos guardados allí: los "ranchos despensas" mencionados por Burmeister para la zona años antes (ARDISSONE, 1937) y por último menciona también los hoyos para guardar papas, sobre los cuales hablaremos en esta sección.

La parición de las papas que los humanos siembran y de aquellas también que se dan en el cerro tiene lugar en la tierra, es allí donde crían a sus guaguas y es una vez que esto ha tenido lugar, que se las puede cosechar, sea en uno u otro ámbito. Dentro del trabajo publicado por Pratec (1999) se recopila el testimonio de Santos Vilca Cayo de la parcialidad aymara de Aynacha Wat'asani en el distrito de Tilali, Puno, quien dice:

Cuando llega su época (septiembre, octubre y noviembre) con mucho cuidado tenemos que tratar a las semillas, porque en esa época va a entrar a una etapa de ser madre. Entonces necesariamente hay que darle de vestir, que consiste en dar tierra a las plantas, cuidar su salud. Así criamos con mucho cariño y respeto, igual ellas también nos criarán. La Ispalla es la propia mujer, es la misma madre que nos cría y la

\footnotetext{
${ }^{9}$ Esto no quita que, como producto de la crianza, otras cosas también se almacenen (vg. carne desecada: charqui o chalona) compartiendo a veces los mismos espacios físicos con las plantas.

10 También llamado "Pirwa"/"Pirgua" o "Troje"; el primer término puede referir además a un amontonamiento antes que a una estructura constructiva (BUGALLO y VILCA, 2011) lo cual se ve claramente en el caso de sectores con alfa pirguada en Huachichocana.
}

Espaço Ameríndio, Porto Alegre, v. 8, n. 1, p. 59-82, jan./jun. 2014. 
VERÓNICA SOLEDAD LEMA - Hacia una cartografía de la crianza...

criamos también. Las semillas nuevas son las mujeres jóvenes y bonitas que pueden producir más, mientras las semillas que ya han permanecido por muchos años son las mujeres o madres cansadas... (PRATEC, 1999, p. 16).

Es también la tierra la que se cansa al sembrarse muchos años en ella, en Huachichocana un sembrador nos comentó que estaba por abrir una nueva parcela al darse cuenta que la tierra ya no tenía fuerza para la papa, lo cual se notaba porque las papas vienen pequeñas, manteniéndose el vínculo patología - cuerpo. En esta comunidad se siembra mayormente papa blanca, collareja y ojo de señorita (ocasionalmente la chacarera), todas consideradas papas criollas ${ }^{11}$, a diferencia de la papa abajeña que se siembra en los sectores más bajos de la comunidad y viene de los valles. Antes, sabían sembrar también la papa tuni que se cocina muy rápido. La collareja y la ojo de señorita son también de cocción rápida, la blanca tarda más y la abajeña aún más. Aquí, al igual que en otras comunidades puneñas del NOA, además de la morfología de los tubérculos (forma, color, cantidad de yemas, entre otros aspectos), el tiempo de cocción de los mismos resulta algo característico y distintivo de cada tipo o variedad de papa. Por el contrario, los tubérculos de las papas yutas ${ }^{12}$ o papas del cerro tardan mucho en cocinarse y son amargos ${ }^{13}$. La homología de cuerpos entre papas criollas y papas del cerro se ve en que, al sacarlas de la tierra, si su cáscara se separa fácilmente, es que están tiernas, es decir, no están en su punto justo de maduración para cosecharlas ${ }^{14}$.

En los campos de Tascal (Huachichocana) vimos como, tras cavar (cosechar) las papas, aparecían las papas erakas portando sus guagas que asemejan en sus cuerpos al de aquellos humanos que las sembraron o bien a ciertos animales- y vimos allí también, junto a las

\footnotetext{
${ }^{11}$ Este término de criolla/o se aplica también a otros cultivos adaptados por largos períodos a los ámbitos de cuidado humano, como por ejemplo el alfa criolla (ver LEMA, en prensa). Asimismo, este términos se usa para las personas (humanas) cuando se encuentran incorporadas y adecuadas a la vida y ritmos de la unidad familiar.

${ }^{12}$ En Huachichocana nos refirieron que yuto quiere decir pequeño.

${ }^{13}$ Otras plantas como la Charagua/cebolla del cerro/cebolla del campo y el zapallito del zorro son también caracterizadas como amargas en Huachichocana.

${ }^{14}$ El término tierno se usa también para otros productos cuando no están listos para ser cosechados, como la lana de las ovejas de la hacienda, lo que se quiere señalar es que tanto en el caso de las papas que cría el cerro como las que cría el Hombre, esto se ve en la cáscara.
}

Espaço Ameríndio, Porto Alegre, v. 8, n. 1, p. 59-82, jan./jun. 2014. 
VERÓNICA SOLEDAD LEMA - Hacia una cartografía de la crianza...

hijas, las papas madre, reconociéndose a las que más han dado por su interior vaciado, habiendo quedado tan solo su cáscara. A diferencia de las otras papas, se procura no cosechar a las papas madre y dejarlas en la tierra donde han sabido parir.

Estas hijas, esta cosecha, alimentará -criará- a la familia que las sembró -que las crió- pero también serán, algunas de ellas, futuras madres. Esas futuras madres, son ahora papas semilla, elegidas por una forma particular (en el caso de las papas blancas han de ser no muy grandes, notablemente más largas que anchas ${ }^{15}$ ), por tener muchos ojos -yemas de las que saldrán los vástagos, las guagas- y cuidando que no tengan señales de haber sido comidas por el gusano. Al momento de elegirlas, ciertas tonalidades de las cáscara indicarán si eran de un tipo u otro (collarejas o blancas), o bien si se habían mezclado. Al preguntar si se entreveraba la papa criolla con la del cerro, nos dijeron que sí, pero que eso se percibe sólo al momento de cocinar las primeras, ya que tardarán más en hacerlo, sin que le cambie prácticamente el sabor.

Tras la selección para consumo y de las papa semilla -separando las erakas ${ }^{16}$, las cuales se regalan también a quienes participaron en la cosecha- las mismas se guardan en bolsas. Las papas para consumo se clasifican en grupos de tamaño (chicas, medianas y grandes) sobretodo si son para la venta, siendo las más pequeñas casi siempre para la hacienda. Antes, saben decir, se guardaban en pozos, hoyos de papa de unos 1.50 metros de profundidad por 1 metro de diámetro, los más grandes. Cada grupo clasificado - la papa menuda, la medianita y la más grande- se ponía en hoyos distintos, se cubría con madera y paja, o piedras planas, sellándolo finalmente con barro. Así, la cosecha cavada entre marzo y abril, duraba hasta septiembre u octubre, con iguales caracteres que recién cosechada, sin que se achuñara. Estos hoyos de papa -al igual que los almacenes o despensas donde se guardan otras cosechas- los hemos visto hasta el momento en las casas y no en los puestos de Huachichocana. Allí nos han mostrado los viejos hoyos para papas que hacían los abuelos, generalmente agrupados en un mismo sector próximo a las piezas de las casas o entre estas y los campos de

\footnotetext{
${ }^{15}$ Esta misma forma era muy evidente durante la cosecha en las papas madre.

${ }^{16}$ Consideradas como papas illas en otros sectores de los Andes (APAZA TICONA, 2000).
}

Espaço Ameríndio, Porto Alegre, v. 8, n. 1, p. 59-82, jan./jun. 2014. 
VERÓNICA SOLEDAD LEMA - Hacia una cartografía de la crianza...

cultivo. Estos hoyos guardaban la cosecha clasificada tras ser cavada en los diversos sembradíos de papa de la familia. En otros casos (*) es en la tierra de la misma chacra donde se elabora el hoyo para guardar las papas, ocas y mashuas de esa misma chacra. Si bien estas se ubican a grandes alturas donde las familias no residen, no se baja y reúne la cosecha en la casa, sino que cada chacra tiene su "almacén". En cambio, en las chacras de abajo, pertenecientes a una misma familia, las semillas de las distintas variedades de maíz se guardan, tras la cosecha, en un almacén común en la vivienda. En Huachichocana se usan viejas construcciones o casas mochas presentes entre las casas y los espacios de cultivo, para pirguarl7 alfa o maíz. En el caso de este último, se separan las mazorcas en tres grupos: para consumo, para la hacienda y para el maíz. Estas últimas son mazorcas enteras, eligiéndose las mejorcitas, que son luego desgranadas al momento de sembrar. También en otras residencias puneñas del NOA (en el paraje de Aguas Calientes, comunidad del Chañi) pueden verse recintos construidos dentro de los sembradíos o rastrojos para pirguar la cosecha.

Sea semilla, sea para consumo de la familia humana o de la hacienda o para intercambio, todo se almacena bajo modalidades $y$ materialidades diversas (silos muy visibles, hoyos casi imperceptibles), pero siempre en el ámbito de sociabilidad ampliada de las unidades domésticas, sobretodo en las casas antes que en los puestos, estando las primeras más vinculadas con el laboreo agrícola 18 y la crianza de las plantas (LEMA, en prensa). Ahora me interesa reflexionar a partir de esto, en torno a dos aspectos: la relación del almacenaje con las trayectorias de cambio evolutivo a nivel de diversidad biocultural y la relación del almacenaje con la crianza del animu de los alimentos. Esto lo hago a nivel exploratorio y como campo de indagación donde se ahondará a futuro.

Como práctica situada, la crianza irá narrando "micro historias naturales" en los distintos conjuntos discretos que nuestro saber

\footnotetext{
${ }^{17}$ En algunas comunidades de la Quebrada de Humahuaca se llama también pirgua a una mazorca grande a la que se unen dos ó tres más, la cual se florea, haciéndola representativa de la fertilidad y el multiplico del alimento en las despensas, siendo este maíz pachamama una "mamala" o "illa" del maíz en relación con la reproducción y fertilidad de las cosechas (BUGALLO Y VILCA, 2011).

${ }^{18}$ Los sembradíos y huertos se constituyen en un recurso material y simbólico distintivo y definitorio de la casa, su conformación y dinámicas.
}

Espaço Ameríndio, Porto Alegre, v. 8, n. 1, p. 59-82, jan./jun. 2014. 
VERÓNICA SOLEDAD LEMA - Hacia una cartografía de la crianza...

académico reconoce como discontinuidades (taxones, morfotipos, especies) ${ }^{19}$, por lo cual puede uno ir de la microhistoria natural de las plantas criadas a la macrohistoria evolutiva de los taxa. A las diferencias espaciales y ambientales -sobretodo altitudinales en los Andes- que influyen en que ciertas plantas den o no su producto en un lugar u otro, se suman las acciones, incluso la suerte (BUGALLO y VILCA, 2011; PAZZARELLI, 2013), del criador. Estas acciones son muchas y de diversa índole, aquí tomaré por caso la selección de semillas y la espacialidad de su almacenamiento.

En el caso del maíz y la papa, la selección de los ejemplares semilla es exclusivamente por su exterioridad y la medida en la cual la misma refleja cierto estado interno, particularmente, la salud. Elegir ejemplares sanos es una condición sine qua non para los ejemplares semilla, al contrario que para aquellos que alimentaran a humanos o a la hacienda. Luego, cada conjunto de semillas que serán las futuras madres de su tipo o variedad (vg. papa blanca, collareja, maíz blanco, maíz amarillo) se elijen por rasgos netamente morfológicos, si bien el tipo o variedad es reconocido por los humanos por múltiples atributos. Muchos de estos atributos que llevan a que la familia decida criar una variedad determinada no se pueden ver al momento de la selección de la semilla, siendo el caso de cruzamientos con papas del cerro detectable sólo al momento de la cocción, ya mencionado, un ejemplo de ello. La exterioridad, el cuerpo en su sentido más restringido, morfológico, es aquí determinante para la elección de semillas y la trayectoria futura de su historia como tipo o variedad.

Cuando el almacenamiento se da en las casas, se destina allí un espacio donde se reunirá toda la cosecha de la familia, la partición de terrenos en las áreas sembradas no generará trayectorias evolutivas particulares, esto permitirá un flujo génico entre los ejemplares de las distintas chacras de una familia que devienen como unidad. En cambio, si las chacras se encuentran en sectores donde no hay casas (*), será la tierra misma de cada chacra, que le posibilitó a los humanos criar y a las

\footnotetext{
${ }^{19}$ Me interesa particularmente que haya un diálogo entre ambos tipos de saberes, no solo apuntando a la multivocalidad y los descentramientos epistémicos y ontológicos, sino también por la necesidad que existe de mayor fluidez en la comunicación y entendimiento de este tipo de aspectos, dado su rol político en la planificación y aplicación de "planes de desarrollo" a nivel local.
}

Espaço Ameríndio, Porto Alegre, v. 8, n. 1, p. 59-82, jan./jun. 2014. 
VERÓNICA SOLEDAD LEMA - Hacia una cartografía de la crianza...

papas parir, la que también albergue y ampare a las semillas que vio nacer en su seno. En este caso, cada chacra con su hoyo asociado generarán un único trayecto evolutivo -ya que en vez de flujo hay aislamiento genético- durante varios años, hasta que se decida dejar descansar la tierra.

Las prácticas vinculadas a sembrar conjuntos que son mezclas de variedades de cada cultivo que se cría es una acción conciente y dirigida por parte de los sembradores, ya que reconocen que ello les asegura la cosecha, puesto que en caso de que no haya buenas condiciones para su crecimiento, algo siempre obtendrán al momento de cosechar; esto se percibe en las palabras de Don Santos Yujra de la Parcialidad de Amsta Huatasani:

Yo siempre, siembro mezclado las variedades de oca, hay diferentes variedades, como qheñi apilla, anq'o qheni, negro ch'isme, entre otros. Cuando sembramos así en años de sequía siempre hay alguito, más bien el zorrino nomás a veces nos hace fracasar (PRATEC, 1998, p. 156).

Incluso, pueden surgir agradables sorpresas: Don Feliciano Cañazaca de la parcialidad de Japisse-Conima, comenta:

Cuando escarbamos la chacra de la oca, vemos aparecer otras variedades, el año pasado yo no he sembrado ocas blancas y ahora en cosecha cuando hemos escarbado aparecieron, de igual manera sucede con los qheñis (PRATEC, 1998, p. 156).

En todo lo anterior influyen, por supuesto, las prácticas de intercambio, regalo y adquisición de nuevas semillas.

Pero estas plantas que son sujetos, criadoras y criadas, pasan por ciclos donde su interioridad se manifiesta en una naturaleza cambiante: semillas, madre y alimento, la cual es atendida y amparada por los humanos durante su transformación. Bugallo y Vilca (2011) señalan como el almacenamiento debe realizarse de tal manera que el ánimu de alimentos y semillas no escape. Envolver los productos en las despensas permite que sus fuerzas vitales crezcan, pero también que sus cuerpos se reproduzcan (PAZZARELLI, 2012 y 2013). Es por ello que el modo de almacenar los granos sigue ciertas prescripciones como chayarlos y

Espaço Ameríndio, Porto Alegre, v. 8, n. 1, p. 59-82, jan./jun. 2014. 
VERÓNICA SOLEDAD LEMA - Hacia una cartografía de la crianza...

sahumarlos para alimentar su animu, así como también aportar ritualmente a su multiplico (ver nota 16), como dicen los autores:

Esta relación entre la duración de lo que se guarda y la reproducción de esa misma especie, si bien pareciera hablar de aspectos muy diferentes -un maíz recogido, cosechado y almacenado por un lado, y un maíz vivo como semilla que brota y crece, por otro- en realidad está refiriendo al ánimu del maíz, que posibilita a la vez su duración como alimento y su reproducción, como especie. Es decir se trata de un maíz vivo (BUGALLO y VILCA, 2011, n. p.).

Esto que los autores ven en la Puna argentina también está presente en otras comunidades andinas, donde si no se llevan a cabo estas prescripciones en los almacenes puede ocurrir que "algunas semillas se comen a las otras o se van volando porque tienen alas" (ROLDÁN CHÁVEZ et al., 2007, p. 40). Así como se crían plantas en las "chacras", también se crían semillas en los almacenes.

\section{Hilvanando algunas reflexiones finales}

Las plantas en Ayllu se acompañan tanto en la chacra, como en la uyaqa, el almacén y en el paisaje. Esta convivencia es para que se contagien el ánimo, por ejemplo, para que tengan fortaleza como la piedra del río (TAPIA y TORRES, 2002, p. 18).

Este trabajo tiene la intención de presentar un ejercicio analítico aún en desarrollo- donde se procuró entender las particularidades de las relaciones que las plantas mantienen con humanos y no humanos en la región andina. Particularmente se indagó en como ello se vincula a los espacios, las materialidades, exterioridad y "cuerpos" que constituyen influyen y reflejan las trayectorias de cambio en las poblaciones vegetales criadas (silvestres, cultivadas, domesticadas o malezoides). La interioridad particular de criadores y criados es un elemento a considerar también, puesto que hace a la exterioridad y a las condiciones "optimas" de la crianza.

Se procuró trazar una cartografía de la crianza y analizar la espacialidad de las prácticas que están involucradas en la misma, 
VERÓNICA SOLEDAD LEMA - Hacia una cartografía de la crianza...

entendiéndolas desde su aspecto situado, yendo desde el paisaje más general a los ámbitos de crianza humana, siendo estos últimos los domicilios de humanos criadores y de sus criados (plantas, animales, otros humanos, todos parte de una red de relaciones "familiares") donde se intenta asegurar la fertilidad y fecundidad con prácticas situadas en los campos, los almacenes y la cocina.

La crianza implica fluidez entre ámbitos, porosidad de espacios, lo doméstico es un ámbito de crianza humana que no puede entenderse en términos fijos o estrictos, las prácticas son dinámicas y los ámbitos de crianza de humanos y no humanos se superponen entre si, diluyéndose mutuamente los límites. Las "micro-historias naturales" existen y son en tanto parte de una "macro historia" que fluye en el patrón dendrítico de la crianza, una gramática que habilita lo doméstico -como habitar la crianza-, pero no necesariamente lo domesticado.

\section{Agradecimientos}

A las familias de la comunidad aborigen de Huachichocana, por su calidez, amistad y por compartir con nosotros sus días y saberes. A los pobladores de Rachaite y Coranzulí a quienes tanto me gustaría volver a visitar. A Jorge Tomasi y Francisco Pazzarelli por haberme invitado a participar de la mesa "Cartografías de lo doméstico en los Andes: prácticas, relaciones y espacialidades en torno a casas, cocinas y canchas" (Séptimo congreso de la Asociación de estudios bolivianos, Sucre, 2013) donde una primera versión de este trabajo fue presentada. Todo lo aquí escrito es responsabilidad exclusiva de la autora.

\section{Bibliografía}

ALDUNANTE, Carlos et al. Estudio etnobotánico en una comunidad precordillerana de Antofagasta: Toconce. Boletín del Museo de Historia Natural de Chile, Santiago, n. 38, p. 183-223, 1981.

APAZA TICONA, Jorge. Cosmovisión andina de la crianza de la papa. In: VAN KESSEL, Juan; LARRAÍN BARROS, Horacio (Org.). Manos sabias para criar la 
VERÓNICA SOLEDAD LEMA - Hacia una cartografía de la crianza...

vida: tecnología andina. Quito: Abya-Yala, 2000. p. 107-128.

APAZA TICONA, Jorge; GORDILLO CONDORI, Valeriano; CUTIPA Sabino. La Crianza Mutua en las Comunidades Aymaras. Puno: Asociación Chuyma de Apoyo Rural Chuyma Aru, 1998.

ARDISSONE, Romualdo. Silos de la Quebrada de Humahuaca. Relaciones de la Sociedad Argentina de Antropología, Buenos Aires, n. 1, p. 117-129; 180-189, 1937.

ARNOLD, Denise; YAPITA, Juan de Dios. Madre Melliza y sus crías: Ispall Mama wawampi, Antología de la papa. La Paz: Hisbol/Ilca, 1996.

BEEBE, Stephen et al. Wild-weedy-crop complexes of common bean (Phaseolus vulgaris L., Fabaceae) in the Andes of Peru and Colombia, and their implications for conservation and breeding. Genetic resources and crop evolution, n. 44, p. 73- 91, 1997.

BUGALLO, Lucila; VILCA Mario. Cuidando el ánimu: salud y enfermedad en el mundo andino (Puna y Quebrada de Jujuy, Argentina). Nuevo Mundo Mundos Nuevo, 2011. Disponível em: http://nuevomundo.revues.org/61781. Acesso em: 25 jun. 2013.

BUGALLO, Lucila; TOMASI, Jorge. Crianzas mutuas: el trato a los animales desde las concepciones de los pastores puneños (Jujuy, Argentina). Revista Española de Antropología Americana, Madrid, v. 42, n. 1, p. 205-224, 2012.

CAVALCANTI-SCHIEL, Ricardo. Las muchas naturalezas en los Andes. Perifèria, Barcelona, n. 7, p. 1-11, 2007.

DESCOLA, Philippe. Más allá de naturaleza y cultura. Buenos Aires: Amorrortu Editores, 2012.

GARCÍA, Silvia et al. "Alfa", vega y hortaliza: riego y siembra en Antofagasta de la Sierra, puna catamarqueña. Relaciones de la Sociedad Argentina de Antropología, Buenos Aires, n. XXVII, p. 79-100, 2002.

GIL GARCÍA, Francisco; FERNÁNDEZ JUÁREZ, Gerardo. El culto a los cerros en el mundo andino: estudios de caso. Revista Española de Antropología Americana, Madrid, v. 38, n. 1, p. 105-113, 2008.

GLEASON, Kathryn. To bound and to cultivate: an introduction to the archaeology of gardens and fields In: MILLER, Naomi; GLEASON, Kathryn (Org.). The archaeology of gardens and fields. Philadelphia: University of Pennsylvania Press, 1994. p. 1-24.

GÖBEL, Bárbara. Identidades sociales y medio ambiente: la multiplicad de los significados del espacio en la Puna de Atacama. Cuadernos del Instituto Nacional de Antropología y Pensamiento Latinoamericano, Buenos Aires, n. 19, p. 267-296, 2000/2002.

Espaço Ameríndio, Porto Alegre, v. 8, n. 1, p. 59-82, jan./jun. 2014. 
VERÓNICA SOLEDAD LEMA - Hacia una cartografía de la crianza...

GRILLO FERNÁNDEZ, Eduardo. El paisaje en las culturas andina y occidental moderna In: GRILLO FERNÁNDEZ, Eduardo et al. (Org.). Crianza andina de la chacra. Lima: PRATEC, 1994. p. 9-46.

HABER, Alejandro La casa, el sendero y el mundo: significados culturales de la arqueología, la cultura material y el paisaje en la Puna de Atacama. Estudios atacameños, San Pedro de Atacama, n. 14, p. 373-392, 1997.

Una arqueología de los oasis puneños: domesticidad, interacción e identidad en Antofalla, primer y segundo milenios d.C. Córdoba: Jorge Sarmieno EditorUniversitaslibros, 2006.

HARLAN, Jack. Crops and man. Madison: American Society of Agronomy, 1992.

HARRIS, David. An evolutionary continuum of people-plan interaction. In: HARRIS, David; HILLMAN, Gordon (Org.). Foraging and Farming: the evolution of plan exploitation. Londres: Unwin Hyman, 1989. p. 11-26.

HILLMAN, Gordon; DAVIES, M. Stuart. Measured domestication rates in wild wheats and barley under primitive cultivation, and their archaeological implications. Journal of World Prehistory, vol. 4, n. 2, p. 157-222, 1990.

HODDER, Ian. Theory and practice in archaeology. Londres: Routledge, 1992.

LEMA, Verónica. Huertos de altura: el manejo humano de especies vegetales en la puna argentina. Revista de Antropología, Rosario, n. XII, p. 173-186, 2006.

Domesticación vegetal y grados de dependencia ser humano-planta en el desarrollo cultural prehispánico del Noroeste Argentino. 2009. 788 f. Tesis (Doctorado en Ciencias Naturales)- Facultad de Ciencias Naturales y Museo, Universidad Nacional de La Plata, La Plata, [2009].

Crianza mutua: una gramática de la sociabilidad andina. Actas de la $\mathbf{X}$ Reunión de Antropología del Mercosur. CD Room. 2013.

Criar y ser criados por las plantas y sus espacios en los Andes septentrionales de Argentina. In: BENEDETTI, Alejandro; TOMASI, Jorge (Org.). Espacialidades altoandinas: avances de investigación desde el Noroeste argentino. En prensa.

MARTÍNEZ, Gabriel. El sistema de los Uywiris en Isluga. Anales de la Universidad del Norte, Santiago, n. 10, p. 255-327, 1976.

MAYER, Enrique. Casa, chacra y dinero: economías domésticas y ecología en los Andes. Lima: IEP, 2004.

PAZZARELLI, Francisco. Arqueología de la comida: cultura material y prácticas de alimentación en Ambato. 2009. 560 f. Tesis (Doctorado en Ciencias Antropológicas)- Facultad de Filosofía y Humanidades, Universidad Nacional de

Espaço Ameríndio, Porto Alegre, v. 8, n. 1, p. 59-82, jan./jun. 2014. 
VERÓNICA SOLEDAD LEMA - Hacia una cartografía de la crianza...

Córdoba, Córdoba, [2012].

Sin lo de adentro, el chivo no se forma: notas sobre 'interioridades' y 'exterioridades' en los Andes jujeños. Actas de la X Reunión de Antropología del Mercosur. CD Room. 2013.

POCHETTINO, María Lelia; LEMA, Verónica. La variable tiempo en la caracterización del conocimiento botánico tradicional. Darwiniana, Buenos Aires, v. 46, n. 2, p. 227-239, 2008.

PORCEL GIRA, Santiago; QUISPE FLORES, Román. Concepciones originarias sobre la papa. Sucre: Talleres gráficos "Gaviota del sur”, 2010.

PRATEC (PROYECTO ANDINO DE TECNOLOGÍAS CAMPESINAS). La crianza mutua en las Comunidades Aymara. Lima: Pratec, 1998.

Crianza andina de la agrobiodiversidad: experiencias de conservación in situ de plantas nativas cultivadas en el Perú y sus parientes silvestres. Lima: Pratec, 1999.

QUESADA, Marcos. Paisajes agrarios del área de Antofalla: procesos de trabajo y escalas sociales de la producción agrícola. (Primer y segundo milenios d.C.). 2007. 523 f. Tesis (Doctorado en Ciencias Naturales)- Facultad de Ciencias Naturales y Museo, Universidad Nacional de La Plata, La Plata, [2007].

QUESADA, Marcos; KORSTANJE, Alejandra. Cruzando estructuras: el espacio productivo y su entorno percibido desde las prácticas cotidianas. In: ALBECK, María Ester; SCATTOLIN María Cristina; KORSTANJE, María Alejandra (Org.). EI hábitat prehispánico: Arqueología de la arquitectura y de la construcción del espacio organizado. San Salvador de Jujuy: UNJU, 2010. p. 123-153.

QUESADA, Marcos; LEMA. Carolina. Los potreros de Antofagasta: trabajo indígena y propiedad (Finales del siglo XVIII y comienzos del XIX), Andes. Antropología e Historia, Salta, n. 22, p. 247-273, 2012.

QUINTEROS, Alfredo. El monte es nuestro padre, cuando el monte muere, sus hijos mueren también. In: ARÉVALO, Mario et al (Org.). Hacer brillar la chacra: agricultura campesina alto amazónica, San Martín. Lima: PRATEC, 1999. p. 95-111.

QUISO CHOQUE, Víctor Kayuni yapu (chacra con patas) Crianza de alpacas y llamas en la comunidad de Ajanani Wajra K'ucho-Puno. In: GRILLO FERNÁNDEZ, Eduardo et al. (Org.). Crianza andina de la chacra. Lima: PRATEC, 1994. p. 233-314.

RENGIFO VÁSQUEZ, Grimaldo. Vivencia alto amazónica. In: ARÉVALO, Mario et al. (Org.). Hacer brillar la chacra: agricultura campesina alto amazónica, San Martín. Lima: PRATEC, 1999. p. 113-140.

El bienestar en la concepción andino-amazónica. Lima: Pratec, 2002.

Espaço Ameríndio, Porto Alegre, v. 8, n. 1, p. 59-82, jan./jun. 2014. 
VERÓNICA SOLEDAD LEMA - Hacia una cartografía de la crianza...

RIVERA ANDÍA, Juan Javier. Apuntes sobre la alteridad constituyente en los Andes. Ambivalencias rituales y lingüísticas sobre un espacio imaginario. Revista Española de Antropología Americana, Madrid, v. 38, n. 1, p. 191-215, 2008.

ROLDÁN CHÁVEZ, Agripina; MEDINA HINOSTROZA, Tulio; SIGÜEÑAS SAAVEDRA, Manuel. Fiestas y rituales en la conservación de la agrobiodiversidad en Perú. Lima: SLM Grafic, 2007.

TAPIA, Mario; TORRES, Juan. Parientes silvestres de los cultivos nativos en el Perú. Memorias del Seminario - Taller "Parientes Silvestres de los Cultivos Nativos en el Perú", Universidad Nacional Agraria La Molina, Lima, Perú; organizado por el Proyecto In Situ y la Universidad Nacional Agraria La Molina. 2002.

TOMASI, Jorge. Geografías del pastoreo: territorios, movilidades y espacio doméstico en Susques (provincia de Jujuy). 2011. 433 f. Tesis (Doctorado en Geografía)- Facultad de Filosofía y Letras, Universidad Nacional de Buenos Aires, Buenos Aires, [2011].

TORRES GUEVARA, Juan; PARRA RONDINEL, Fabiola. Parientes silvestres de plantas nativas cultivadas andinas (Perú): los sachas. Lima: CCTA, 2008.

VALLADOLID RIVERA, Julio. Agricultura campesina andina: crianza de la diversidad de la vida en la chacra. In: GRILLO FERNÁNDEZ, Eduardo et al. (Org.). Crianza andina de la chacra. Lima: PRATEC, 1994. p. 315-378.

VAN KESSEL, Juan. La economía andina de crianza; actores y factores metaeconómicos. Cuadernos de Investigación en Cultura y tecnología andina, Iquique, $\mathrm{n}$. 22, p. 1-56, 2003.

VILCA, Mario. Más allá del "paisaje". El espacio de la puna y quebrada de Jujuy: ¿comensal, anfitrión, interlocutor? Cuadernos FHyCS-UNJU, San Salvador de Jujuy, n. 36, p. 245-259, 2009.

Espaço Ameríndio, Porto Alegre, v. 8, n. 1, p. 59-82, jan./jun. 2014. 